\title{
CAPÍTULO 07: EXPECTATIVA VERSUS REALIDADE: SATISFAÇÃO COM O ENSINO REMOTO ENTRE UNIVERSITÁRIOS DURANTE A PANDEMIA POR COVID-19
}

\section{CAPÍTULO 07: EXPECTATION VERSUS REALITY: SATISFACTION WITH REMOTE EDUCATION BETWEEN UNIVERSITY DURERS DURING THE PANDEMIC BY COVID-19}

\section{CHAPTER 07: EXPECTATIVA VERSUS REALIDAD: SATISFACCIÓN CON LA EDUCACIÓN A DISTANCIA ENTRE UNIVERSIDADES DURANTE LA PANDEMIA POR COVID-19}

\begin{abstract}
Taciana Melo Cruz ${ }^{1}$; Patrícia Clarindo Zelykovic ${ }^{2}$; Vitória Beatriz da Silva ${ }^{3}$; Mirtes Queiroz de Alencar Melo ${ }^{4}$;
\end{abstract} Tatiana de Paula Santana da Silva ${ }^{5}$

DOI: https://doi.org/10.31692/978-65-88970-04-1.71-76

\section{INTRODUÇÃO}

A pandemia da COVID-19 tem trazido inúmeras repercussões tanto para comunidade em geral, como para profissionais, gestores da saúde e autoridades políticas nacionais, além disso, o surgimento do vírus tem sido responsável por crises econômicas no mundo e mudanças drásticas nas rotinas de diversos setores e instituições (GOMES et al., 2020)

Essa iniciativa trouxe novos contextos e dinâmicas em todo o mundo, para praticamente todos os setores e serviços da sociedade, comércios foram fechados, serviços foram suspensos, instituições foram fechadas, hospitais foram criados, a gestão estratégica e a política mundial foi impactada. No contexto educacional, as mudanças também se fizeram presentes, as escolas fecharam e as aulas foram paralisadas tanto para o ensino fundamental como para o médio e superior. De acordo com os relatórios das Nações Unidas (2020) cerca de "1,5 bilhão de estudantes em pelo menos 174 países ficaram fora da escola em todo o mundo."

Essas mudanças abruptas nas modalidades de ensino não têm sido encaradas de forma satisfatória tanto para alunos como para docentes e, nesse sentido apesar dos esforços de ambas as partes se tornam importante avaliar a Satisfação com o ensino remoto universitários durante a pandemia por Covid-19, sendo este o objetivo do presente estudo.

\footnotetext{
${ }^{1}$ Fonoaudiologia, Centro Universitário São Miguel (UNISÃOMIGUEL), taciana melo28@

${ }^{2}$ Fonoaudiologia, Centro Universitário São Miguel (UNISÃOMIGUEL), patyczelykovic

${ }^{3}$ Fonoaudiologia, Centro Universitário São Miguel (UNISÃOMIGUEL), beatrizcs

${ }^{4}$ Fonoaudiologia, Centro Universitário São Miguel (UNISÃOMIGUEL), mirtesclube

${ }^{5}$ Doutora, Centro Universitário São Miguel (UNISÃOMIGUEL), tatianapss2@ gmail.com
} 


\section{FUNDAMENTAÇÃO TEÓRICA}

Gomes e colaboradores (2020) citaram a descoberta do vírus que ocorreu em dezembro de 2019, sendo denominado SARS-CoV-2, que causa a doença COVID-19 assim denominada pela Organização Mundial da Saúde (OMS). O SARS-CoV-2 surgiu inicialmente na cidade de Wuhan, na China, e se espalhou rapidamente por todo o mundo. Já em 30 de janeiro de 2020, a OMS reconheceu o surto dessa nova doença como uma emergência de saúde pública de importância internacional, que é considerado o maior nível de alerta. Posteriormente, no dia 11 de março de 2020, a OMS caracterizou a COVID-19 como uma pandemia.

Dado o alerta pela de emergência de saúde pública, as aulas de todas as instituições de ensino particular e público foram suspensas, porém as instituições de ensino utilizaram de forma vantajosa o ensino remoto como uma estratégia de aprendizado à distância, trazendo segurança aos alunos, favorecendo assim o isolamento social.

Joye e colaboradores (2020) além de confirmar o panorama atual da rede educacional, enfatiza que apesar do cenário, muitas instituições optaram por mudar sua dinâmica de ensino, onde professores foram dispensados de suas atividades escolares e acadêmicas para fazer trabalho remoto.

Segundo Ministério da Saúde (2020) desde o início do isolamento social, o Ministério da Educação - MEC vem acompanhando o crescimento de instituições que aderiram as aulas com Tecnologia da Informação e Comunicação TIC/Remotas, dentre elas, na rede Federal de Educação Profissional, Científica e Tecnológica, 22 das 44 instituições estão com atividades remotas, dando a porcentagem de 53,6\% do total, ou seja, 514 mil alunos, 24 mil professores e 19 mil técnicos.

Com o momento atual, as ações de ensino remoto destacam-se como uma importante estratégia, porém é essencial entender que essa modalidade apesar de bastante consolidada pode ter algumas limitações, principalmente no tocante as ações práticas para o ensino dos cursos de saúde.

Mediante essa perspectiva Joye e colaboadores (2020) constataram que:

\footnotetext{
"Várias questões precisam ser consideradas para que essa alternativa seja efetiva para todos os estudantes, o que é um desafio enorme, especialmente considerando que muitos não possuem acesso aos recursos tecnológicos e, até mesmo, muitas escolas não possuem a infraestrutura necessária para sua efetivação.
}

Além disso de acordo com o documento Todos pela Educação, a falta de capacitação dos professores, e infraestrutura inadequada das instituições, podem trazer impactos 
significativos ao processo de aprendizagem sendo extremamente importante avaliar a Satisfação com o ensino remoto entre universitários durante a pandemia por COVID-19, sendo este o objetivo do presente estudo (GOMES et al., 2020).

\section{METODOLOGIA}

A pesquisa é caracterizada como um estudo transversal descritivo com amostra do tipo conveniência não probabilística, compostas por jovens de 18 anos e adultos até a idade de 60 anos, todos devidamente matriculados em curso superior da área de saúde.

O estudo reebeu aprovação ética (parecer $\mathrm{n}^{\circ}$ 4.076.216) e foi conduzido de acordo com a resolução número 466/12, do Conselho Nacional de Saúde do Ministério da Saúde Brasília - DF. Todos os participantes expressão seu consentimento de forma voluntária mediante leitura e assinatura digital do Termo de Consentimento Livre Esclarecido - TCL enviado a partir de formulário eletrônico.

Os critérios de inclusão versaram sobre a frequência em pelo menos duas disciplinas do período e foram excluídos todos os estudantes que deixaram alguma das questões do formulário em branco.

Para coleta dos das informações foi construído pelos pesquisadores um instrumento eletrônico através do serviço de criação de formulários eletrônicos (Google formulário).

O referido formulário foi encaminhado por mala direta (e-mail) para os alunos mediante parceira com os representantes de turma de cada período do curso, que se responsabilizaram em encaminhar o link de acesso ao formulário.

Para a análise dos dados foi criado um banco de dados no Microsoft Excel 2010. Em seguida, as informações colhidas foram tabuladas e analisadas segundo técnica estatística descritiva.

\section{RESULTADOS E DISCUSSÃO}

Em relação a satisfação dos estudantes, sobre o conteúdo abordado, $40 \%$ classificaram o conteúdo e o material estudado como bom. Abaixo de $20 \%$ os entrevistados classificaram o conteúdo e o material estudado como ótimo (gráfico 1). 
Gráfico 1- Distribuição das respostas quanto a satisfação, o conteúdo e ambiente de aulas.

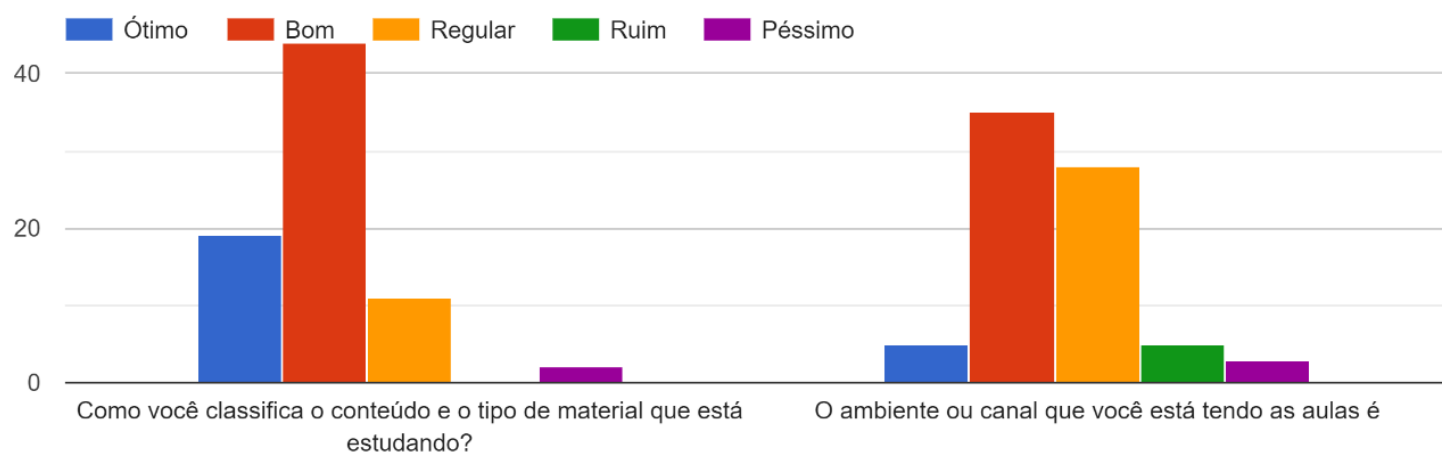

Fonte: Própria (2020).

No que se refere ao ambiente e o canal em que os entrevistados acessaram as aulas, as respostas dos entrevistados ficaram abaixo de $10 \%$ como ótimo e abaixo de $40 \%$ como bom, acima de $20 \%$ os entrevistados caracterizaram como regular, abaixo de $10 \%$ caracterizaram como ruim e muito abaixo de $10 \%$ caracterizaram como péssimo. Relacionado as atividades educacionais, abaixo de $40 \%$ confirmaram que em suas casas tem outras pessoas que fazem o uso de aulas online e também a abaixo de $40 \%$ classificaram que em suas casas não tem pessoas que fazem o uso de aulas online (gráfico 2).

Gráfico 2- Distribuição das respostas quanto ao engajamento nas atividades avaliativas oriundas das disciplinas ofertadas de forma remota.

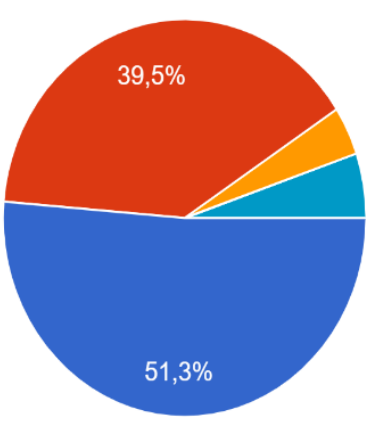

Realizei completamente as AERs.

Realizei parcialmente as AERs e vou completá-las.

Realizei parcialmente as AERs e não consigo completá-las.

Não consegui realizar as AERs.

Não tive acesso a nenhuma AER.

Outro:

Fonte: Própria (2020).

Dosea e colaboradores (2020) apontam que de fato o ensino remoto apesar dos indiscutíveis benefícios quando instaurado em reginmes emergenciais pode apresentar grandes índices de insatisfação e sobre isso o autor aponta que um dos principais motivos relatados por alunos é o sentimento de solidão do aluno, que por vezes sente-se desmotivado pela necessidade de interação, atenção e apoio por parte dos docentes. Esse sentimento pode trazer consequências significativas ao processo de aprendizagem, podendo por exemplo ser motivo de evasão dos alunos das salas. 
Outro ponto que parece ser semelhante ao encontrado em nesse estudo foi a ausência de hábito da autoaprendizagem, que recai sobre a baixa autonomia do estudante, com consequente reflexo na dificuldade de apresentar um papel ativo e interativo e com isso de realizar em sua totalidade as atividades solicitadas pelos docentes nos ambientes de aprendizagem.

Sobre essa questão Macedo e colaboradores (2018) destacam que a ação e interação são de fato pontos fundamentais e colocam o aluno em um papel central no processo de ensino e aprendizagem, ou seja, o discente sai de uma relação vertical, para uma horizontal, na qual o conhecimento não se restringe apenas ao professor. Essa estrutura gera um dinamismo nas relações de ensino, trazendo à tona a relevância da discussão e problematização da realidade, com destaque ao papel centralizado do discente.

\section{CONCLUSÕES}

Os dados analisados revelam de um modo geral uma insatisfação por parte dos discentes quanto ao ensino remoto durante a pandemia por Covid-19, dentre as insatisfações gerais, o ambiente de aprendizagem e as atividades solicitadas foram os aspectos que mais impactaram na satisfação.

Estes dados revelam a necessidade de um maior planejamento por parte das instituições educacionais em situações críticas, como uma emergência pandêmica, tais iniciativas podem impactar em indicadores de maior satisfação e engajamento dos estudantes.

\section{REFERÊNCIAS}

DOSEA, G.S. et al. MÉTODOS ATIVOS DE APRENDIZAGEM NO ENSINO ONLINE: A OPINIÃO DE UNIVERSITÁRIOS DURANTE A PANDEMIA DE COVID19. Interfaces Científicas-Educação, v. 10, n. 1, p. 137-148, 2020.

MACEDO, K.D.S. et al. Metodologias ativas de aprendizagem: caminhos possíveis para inovação no ensino em saúde. Escola Anna Nery, v. 22, n. 3, 2018.

GOMES, V.T.S. et al. A Pandemia da Covid-19: Repercussões do Ensino Remoto na Formação Médica. Revista Brasileira de Educação Médica, v. 44, n. 4, 2020.

MUÑOZ, Rafael. A experiência internacional com os impactos da COVID-19 na educação. Nações Unidas do Brasil. Acesso em, v. 5, 2020.

Assessoria de comunicação social do Ministério da Educação: Mais da metade da Rede Federal 
de Ensino está com atividades remotas; Disponível em: https://www.gov.br/mec/ptbr/assuntos/noticias/maisda-metade-da-rede-federal-de-ensino-esta-com-atividades-remotas . Acesso em: 10 set.2020.

JOYE, C.R.; MOREIRA, M.M.; ROCHA, S.S.D. Educação a Distância ou Atividade Educacional Remota Emergencial: em busca do elo perdido da educação escolar em tempos de COVID-19. Research, Society and Development, v. 9, n. 7, p. e521974299-e521974299, 2020.

EDUCAÇÃO, Todos Pela. Ensino a distância na Educação Básica frente à pandemia da Covid-19. Nota Técnica, 2020.

JOYE, C.R.; MOREIRA, M.M.; ROCHA, S.S.D. Educação a Distância ou Atividade Educacional Remota Emergencial: em busca do elo perdido da educação escolar em tempos de COVID-19. Research, Society and Development, v. 9, n. 7, p. e521974299-e521974299, 2020 . 